\title{
PELATIHAN PENINGKATAN PENGETAHUAN DAN KETERAMPILAN MEMILIH OBAT MATA BAGI TENAGA KESEHATAN DESA CILAYUNG KECAMATAN JATINANGOR
}

\author{
Insan Sunan Kurniawansyah, Iyan Sopyan, dan Soraya Ratnawulan Mita \\ Departemen Farmasetika dan Teknologi Farmasi Fakultas Farmasi Universitas Padjadjaran \\ E-mail: insan.sunan.kurniawansyah@unpad.ac.id
}

\begin{abstract}
ABSTRAK. Obat mata merupakan kebutuhan manusia yang di perlukan untuk mengatasi berbagai keluhan, pemeliharaan atau peningkatan kesehatan mata. Jumlah obat yang banyak dijual di Indonesia dan berbagai promosi yang ditawarkan serta di tunjang dengan mudahnya toko untuk menjual obat tersebut, masyarakat mudah sekali untuk mengonsumsinya tanpa konsultasi dan peresepan dokter. Lebih dari 60\% masyarakat mempraktekkan pengobatan mandiri dan lebih dari 80\% di antaranya mengandalkan obat modern, sehingga jika penggunaannya salah, tidak tepat, tidak sesuai dengan takaran dan indikasinya, akan membahayakan pengguna. Hal ini perlu ditanggulangi dengan penggunaan yang rasional sehingga tingkat kesehatan masyarakat membaik. Pengetahuan penggunaan obat mata yang rasional merupakan salah satu usaha peningkatan kesehatan mata, mencegah kecelakaan mata, melakukan pertolongan pertama bila ada benda asing di mata, mengenal tanda-tanda atau bahaya kerusakan mata dan memahami pemberian obat mata. Obat mata jarang sekali di edukasikan kepada masyarakat sehingga pengetahuannya menjadi kurang akan hal tersebut. Oleh karena itu dilakukan pelatihan dan peningkatan pengetahuan tentang penggunaan obat mata kepada masyarakat, agar nantinya mampu mempertimbangkan promosi iklan obat di pasaran dan mengelola obat di rumah secara benar. Kegiatan yang dilakukan berupa penyuluhan dan pelatihan penggunaan obat mata yang rasional kepada masyarakat Desa Cilayung Kecamatan Jatinangor, yang mana pelaksanaannya dimulai dari pembuatan materi penyuluhan, sosialisasi kepada aparat desa dan masyarakat, pembentukan kelompok sasaran kegiatan, penyuluhan dan pelatihan kepada masyarakat serta pemantauan dan evaluasi hasil kegiatan. Kegiatan ini dilaksanakan berkaitan dengan Program Pengabdian pada Masyarakat Universitas Padjadjaran, yang juga melibatkan kerjasama dengan mahasiswa KKN, unsur pemerintah desa, tokoh masyarakat, dan kader masyarakat Desa Cilayung Jatinangor.
\end{abstract}

Kata kunci: obat mata; pengobatan mandiri; Desa Cilayung

ABSTRACT. Opththalmic drug is one of the human needs in order to overcome a problem or symptoms and to maintain and improve eye health. With the number of drugs that are widely sold in Indonesia and various promotions offered and supported by the convenience of stores to sell these drugs, the people is very easy to consume drugs sold in stores without consulting and Doctor's prescribition. More than $60 \%$ of the people practice self-medication and more than $80 \%$ of them rely on modern medicine so that if its use is wrong, incorrect, not in accordance with the dosage and indications it will endanger the user, and if that is true it will be extraordinary in level of health care so that it can improve the level of public health. Knowledge of the use of rational eye preparation is one of the efforts to improve eye health, prevent eye accidents, make first aid if there are foreign objects in the eye, recognize signs or danger of eye damage and understand eye drug administration. Eye medicine is rarely educated to the public so that people's knowledge is lacking, therefore training and increased knowledge about the use of ophthalmic medicines for the people of Cilayung Village so that later they are able to consider the promotion of advertising drugs on the market and properly manage home remedies. Activity conducted in the form of counseling and training on the use of rational eye medicine to the community in the village, whose implementation began with the making of counseling materials, socialization to village officials and the community, the formation of target groups of activities, counseling and training to the community and monitoring and evaluation of the results of PPM activities. This activity was carried out in connection with the DRPMI Program at Universitas Padjadjaran. This activity also involved collaboration with KKN students, elements of the village government, community leaders, and cadres of the Cilayung Jatinangor Village community.

Key words: Opththalmic drug; self medication; Cilayung Village

PENDAHULUAN

Pengobatan sendiri (self medication) merupakan upaya yang paling banyak dilakukan masyarakat untuk mengatasi keluhan atau gejala penyakit, sebelum mereka memutuskan mencari pertolongan ke pusat pelayanan kesehatan/ petugas kesehatan. Lebih dari $60 \%$ masyarakat mempraktekkan self-medication ini, dan lebih dari $80 \%$ di antara mereka mengandalkan obat modern. Apabila dilakukan dengan benar, maka self-medication merupakan sumbangan yang sangat besar bagi pemerintah, terutama dalam pemeliharaan kesehatan secara nasional. Untuk melakukan self-medication secara benar, masyarakat mutlak memerlukan informasi yang jelas dan dapat dipercaya, dengan demikian penentuan jenis dan jumlah obat yang diperlukan harus berdasarkan kerasionalan.
Pelaku self-medication dalam "mendiagnosis" penyakitnya, harus mampu :

1. Mengetahui jenis obat yang diperlukan.

2. Mengetahui kegunaan dari tiap obat, sehingga dapat mengevaluasi sendiri perkembangan rasa sakitnya.

3. Menggunakan obat secara benar (cara, aturan, lama pemakaian) dan mengetahui batas kapan mereka harus menghentikan self medication yang kemudian segera minta pertolongan petugas kesehatan.

4. Mengetahui efek samping obat yang digunakan sehingga dapat memperkirakan apakah suatu keluhan yang timbul kemudian, merupakan suatu penyakit baru atau efek samping obat.

5. Mengetahui siapa yang tidak boleh menggunakan obat tersebut, terkait dengan kondisi seseorang. 
Pengetahuan di atas jarang sekali dikuasai oleh masyarakat, oleh karena itu perlu dilakukan pemberdayaan masyarakat di dalam peningkatan pengetahuan tentang penggunaan obat untuk diri sendiri, salah satu diantaranya adalah obat mata. (Kurniawansyah dkk, 2018)

Situasi di RW 02 Desa Cilayung memiliki potensi dalam bidang kesehatan masyarakat. Desa Cilayung memiliki satu posyandu yang terletak tidak jauh dari Masjid tempat warga biasa beribadah. Pengelolaan posyandu masih belum terlaksana dengan baik dari segi infrastruktur maupun tenaga kerja. Posyandu Desa Cilayung hanya berukuran $5 \times 5 \mathrm{~m}$ dirasa masih kurang luas untuk menampung warga yang ingin melakukan kegiatan kesehatan. Beberapa kegiatan kesehatan pun terpaksa dilakukan di ruangan serbaguna Masjid terdekat karena alasan kenyamanan dan kuantitas peserta.

Sesuai dengan struktur organisasinya, tenaga kerja pengelola posyandu berjumlah lima orang yang diketuai oleh Ibu Ojah. Ada beberapa tenaga kerja yang harus bekerja ganda, atau memiliki dua tugas dalam mengelola posyandu ini. Dengan latar belakang yang berbeda, tenaga kerja pengelola posyandu tentunya memiliki kelebihan dan keterbatasannya masing-masing. Beberapa tenaga kerja sempat menyelesaikan pendidikannya di Sekolah Menengah Atas tetapi masih ada juga yang hanya lulusan Sekolah Dasar dan tidak fasih membaca.

Menimbang dari hal-hal yang sudah disebutkan diatas, tenaga kerja pengelola posyandu dirasa perlu memiliki pemahaman lebih dalam penggunaan obatobatan. Baik untuk dirinya sendiri, keluarga terdekat hingga para warga yang akan melakukan kegiatan kesehatan. Pengetahuan dan keterampilan dalam memilih obat mata bagi tenaga kesehatan khususnya dan masyarakat pada umumnya sering menjadi kendala dalam perihal swamedikasi berkaitan dengan pengobatan ataupun pencegahan penyakit yang berhubungan dengan mata. Oleh karena itu dengan semakin berkembangnya ilmu pengetahuan terutama mengenai pengembangan obat mata, diperlukan suatu pelatihan kepada tenaga kesehatan, dengan tujuan agar pengetahuan dan keterampilannya lebih meningkat, baik dalam usaha peningkatan kesehatan mata, pencegahan kecelakaan mata, pertolongan pertama bila ada benda asing di mata, dan lebih mengenal tandatanda atau bahaya kerusakan mata serta paham akan pemberian obat mata, yang pada akhirnya mereka bisa menyebarluaskan ilmunya kepada masyarakat terkait dalam hal pemilihan obat mata yang baik dan rasional.

\section{METODE}

Metode yang digunakan dalam kegiatan ini adalah Metode Cara Belajar Ibu Aktif (CBIA) yang merupakan salah satu kegiatan pemberdayaan masyarakat yang dapat digunakan untuk swamedikasi. Metode ini merupakan metode pembelajaran untuk para ibu rumah tangga (dalam hal ini sebagai tenaga kesehatan setempat/posyandu) agar lebih aktif dalam mencari informasi mengenai obat yang digunakan oleh keluarga. Informasi tersebut berguna bagi para ibu antara lain agar mampu mempertimbangkan promosi iklan obat di pasaran dan mengelola obat di rumah tangga secara benar mengingat hasil beberapa survey menyatakan bahwa ibu rumah tangga adalah "key person" dalam penggunaan obat. Selain itu juga agar tujuan selfmedication dapat tercapai secara optimal. Sebagai salah satu upaya pendukung kegiatan pemberdayaan masyarakat dengan menggunakan metode intervensi tersebut di atas, maka perlu disosialisasikan kepada ibu rumah tangga dan kader masyarakat, melalui suatu pelatihan. Untuk ini perlu disusun suatu materi pelatihan Peningkatan Pengetahuan dan Keterampilan Memilih Obat Mata, dengan menggunakan metode ini.

Penyelenggaraan metode CBIA ini berawal dari pengobatan untuk sendiri (self medication) yang banyak dilakukan oleh masyarakat untuk mengatasi keluhan atau gejala penyakit sebelum mereka memutuskan mencari pertolongan ke sarana pelayanan kesehatan maupun petugas kesehatan. Selain itu juga, masyarakat membutuhkan informasi yang benar, jelas dan dapat dipercaya, agar penentuan kebutuhan, jenis, dan jumlah obat berdasarkan kerasionalan. Pengetahuan tersebut di atas, dan pengetahuan tentang gejala serta cara mendiagnosis penyakit jarang sekali dikuasai oleh masyarakat. Masyarakat sering mendapatkan informasi obat melalui iklan obat, baik dari media cetak maupun media elektronik dan ini merupakan jenis informasi yang paling berkesan sangat mudah ditangkap serta sifatnya komersial.

Adapun untuk pelaksanaan metode ini, kegiatan dibagi menjadi 3 tahap, kegiatan I dan II dilakukan dalam kelompok, dan kegiatan III dilakukan secara individual di rumah. Kegiatan I dan II memakan waktu 2 - 3 jam, tergantung dari dinamika kelompok.

Makin tinggi tingkat dinamika, makin besar gairah untuk berdiskusi sehingga akan semakin lama waktu yang diperlukan. Sebaiknya kegiatan dalam kelompok dibatasi maksimal 4 jam. Peserta dibagi dalam kelompokkelompok kecil yang terdiri dari 6-8 orang. Lembar kerja dibagikan kepada tiap peserta. Petunjuk kegiatan diberikan kepada ketua kelompok. Pada Kelompok I, 1 paket obat dibagikan kepada tiap-tiap kelompok, kemudian diminta untuk mengamati kemasan obat, mengelompokkan obat berdasarkan zat aktif bukan berdasarkan indikasi dan mendiskusikan hasil-hasil pengamatan yang dilakukan. Pimpinan ketua kelompok bila perlu dibantu Tutor Narasumber mendiskusikan informasi dalam kemasan, perbedaan dan persamaan kandungan zat aktif dari setiap jenis obat kemudian harga obat.

Pada Kelompok II tahap kegiatan yang dilakukan bertujuan agar peserta pelatihan bisa mencari informasi dari kemasan, dengan cara meneliti setiap tulisan yang tercantum dalam kemasan maupun package insert. Dalam kegiatan ini digunakan lembar kerja yang telah disediakan. Kelengkapan pengisian lembar kerja diharapkan dapat 
memacu aktifitas peserta pada tahap selanjutnya. Dengan dipimpin ketua kelompok, pencarian informasi dilakukan secara bersama-sama, sambil membandingkan kelengkapan informasi dari satu nama dagang dengan nama dagang yang lain. Walaupun kegiatan ini dilakukan dalam kelompok, namun tiap peserta harus mencatat untuk diri masing-masing. Sambil mencatat informasi, peserta sekaligus dapat menelaah secara sederhana, kelengkapan dan kejelasan informasi yang disajikan pada tiap kemasan.

Kegiatan pada kelompok III bertujuan untuk memupuk keberanian peserta mencari informasi sendiri. Perlu dipastikan dahulu bahwa lembar kerja pada kegiatan 2 telah terisi dengan baik. Dalam tahap ini, peserta diminta untuk mengerjakan pencatatan informasi seperti kegiatan 2, terhadap obat yang ada di rumah masing-masing. Setelah menjelaskan kegiatan 3, diskusi ditutup dengan rangkuman oleh salah satu Tutor atau Narasumber, mengidentifikasi kembali temuan-temuan penting yang diperoleh di masing-masing kelompok, dan memberikan pesan-pesan untuk memperkuat dampak intervensi.

\section{HASIL DAN PEMBAHASAN}

Kegiatan PPM Prioritas yang telah dilaksanakan berupa pembuatan materi penyuluhan dan pelatihan, sosialisasi kepada aparat desa dan masyarakat serta pembentukan kelompok sasaran kegiatan. Adapun sebagai kelompok sasaran kegiatan diantaranya adalah ibu-ibu PKK, petugas dan kader posyandu serta aparat desa terkait.

Sebagai solusi, outcome yang diharapkan, dan indikator capaian dari kegiatan PPM ini dapat dilihat pada Tabel 1 berikut:

Tabel 1. Solusi, Outcome yang Diharapkan, dan Indikator Capaian PPM

\begin{tabular}{|c|c|c|c|}
\hline No. & Solusi & $\begin{array}{c}\text { Outcome yang } \\
\text { diharapkan }\end{array}$ & $\begin{array}{l}\text { Indikator } \\
\text { capaian }\end{array}$ \\
\hline 1 & $\begin{array}{l}\text { Pembuatan } \\
\text { program desa } \\
\text { mengenai edukasi } \\
\text { kesehatan yang } \\
\text { berkesinam- } \\
\text { bungan. }\end{array}$ & $\begin{array}{l}\text { Aparat desa } \\
\text { memiliki } \\
\text { program edukasi } \\
\text { kesehatan yang } \\
\text { berkesinambungan. }\end{array}$ & $\begin{array}{l}\text { Tersusunnya } \\
\text { program desa } \\
\text { mengenai edukasi } \\
\text { kesehatan } \\
\text { yang ber- } \\
\text { kesinambungan }\end{array}$ \\
\hline 2 & $\begin{array}{l}\text { Peningkatan } \\
\text { pengetahuan dan } \\
\text { keterampilan } \\
\text { kader kesehatan } \\
\text { tentang } \\
\text { penggunaan } \\
\text { obat mata yang } \\
\text { rasional. }\end{array}$ & $\begin{array}{l}\text { Pengetahuan dan } \\
\text { keterampilan kader } \\
\text { kesehatan tentang } \\
\text { penggunaan obat } \\
\text { mata yang rasional } \\
\text { meningkat. }\end{array}$ & $\begin{array}{l}\text { Meningkatnya } \\
\text { pengetahuan dan } \\
\text { keterampilan } \\
\text { kader kesehatan } \\
\text { tentang } \\
\text { penggunaan } \\
\text { obat mata yang } \\
\text { rasional }\end{array}$ \\
\hline 3 & $\begin{array}{l}\text { Pemberdayaan } \\
\text { masyarakat } \\
\text { sebagai } \\
\text { bekal dalam } \\
\text { swamedikasi } \\
\text { dirinya sendiri } \\
\text { dan pengelolaan } \\
\text { obat dirumah } \\
\text { tangganya. }\end{array}$ & $\begin{array}{l}\text { Masyarakat } \\
\text { memiliki } \\
\text { pengetahuan dan } \\
\text { keterampilan dalam } \\
\text { swamedikasi dan } \\
\text { pengelolaan obat di } \\
\text { rumah tangganya }\end{array}$ & $\begin{array}{l}\text { Masyarakat } \\
\text { semakin } \\
\text { paham akan } \\
\text { swamedikasi } \\
\text { dan pengelolaan } \\
\text { obat di rumah } \\
\text { tangganya }\end{array}$ \\
\hline
\end{tabular}

Melalui kegiatan ini diharapkan peserta dapat mengetahui tentang penggunaan obat mata dan sekaligus dapat melatih kader kesehatan /masyarakat. Selain itu diharapkan kedepan peserta dapat memilih dan memberikan penjelasan mengenai khasiat dan cara penggunaan obat mata kepada anggota rumah tangga yang mengeluh sakit, sebagai pertolongan pertama sebelum mereka membawa ke sarana kesehatan yang terdekat.

Program kegiatan PPM Prioritas yang sudah dilaksanakan ini sangat penting untuk ditindaklanjuti agar program tersebut betul-betul dapat memberikan manfaat yang berarti bagi masyarakat. Keberlanjutan program akan lebih diarahkan pada aspek pembinaan masyarakat/kader kesehatan di dusun masing-masing sebagai pengembangan potensi sumber daya manusia bagi kepentingan kesehatan dan kesejahteraan masyarakat.

\section{SIMPULAN}

Pelaksanaan program PPM Prioritas dalam kegiatan penyuluhan tentang kesehatan, yang mengambil judul "Pelatihan Peningkatan Pengetahuan dan Keterampilan Memilih Obat Mata Bagi Tenaga Kesehatan Desa Cilayung Kecamatan Jatinangor", dapat terlaksana dengan baik atas kerjasama tim PPM Prioritas, mahasiswa KKN dan masyarakat sekitar. Sebagai tolak ukur keberhasilan dari kegiatan yang dilaksanakan, kami dapat mengetahuinya dari sikap masyarakat dan tenaga kesehatan setempat dari kuisioner yang digunakan akan pola penerapan dari pelatihan dan penyuluhan yang telah diberikan, yaitu masyarakat mengetahui manfaat obat mata, pemilihan obat mata dan cara penggunaannya serta dapat menerapkannya untuk kesehatan diri dan keluarga.

Kami tim PPM Prioritas sangat berharap akan kontribusi dari masyarakat sekitar ataupun kader kesehatan masyarakat, baik berupa saran-saran ataupun berupa kerjasama yang dapat meningkatkan taraf hidup sehat dari masyarakat sehingga dengan adanya kegiatan ini dapat memotivasi baik kami selaku tim maupun masyarakat setempat untuk tetap dapat saling memerlukan dalam upaya peningkatan derajat kesehatan masyarakat.

\section{UCAPAN TERIMAKASIH}

Kami tim PPM Prioritas sangat berharap akan kontribusi dari masyarakat sekitar ataupun kader kesehatan masyarakat, baik berupa saran-saran ataupun berupa kerjasama yang dapat meningkatkan tarafhidup sehat dari masyarakat sehingga dengan adanya kegiatan ini dapat memotivasi baik kami selaku tim maupun masyarakat setempat untuk tetap dapat saling memerlukan dalam upaya peningkatan derajat kesehatan masyarakat. Tidak lupa, kami mengucapkan terima kasih yang sebesar-besarnya kepada Direktorat Riset, Pengabdian kepada Masyarakat dan Inovasi yang telah mendukung kegiatan ini. 


\section{DAFTAR PUSTAKA}

Adrian, K. (2018). Penggunaan Obat Tetes Mata yang Tepat. Tersedia online di https://www.alodokter. com/penggunaan-obat-tetes-mata-yang-tepat

Anonim. (2016). Kesehatan Mata dan Penglihatan: Begini Cara Tepat Gunakan Obat Tetes Mata. Tersedia online di https://meetdoctor.com/article/ begini-cara-tepat-gunakan-obat-tetes-mata

Muhlisin, A. (2018). Obat Tetes Mata yang Cocok untuk Anda. Tersedia online di https://mediskus.com/ penyakit/obat-tetes-mata-yang-cocok-untukanda

Anonim. (2018). Tetes Mata Idealnya Digunakan Berapa Lama Setelah Dibuka? Tersedia online di http://www.braito.co.id/tetes-mata-idealnyadigunakan-berapa-lama-setelah-dibuka/

Loebis R. (2016). Tips Penggunaan Obat Tetes Mata yang Efektif. Tersedia online di https://rozalinaloebis. wordpress.com/2016/02/12/tips-penggunaanobat-tetes-mata-yang-efektif/
Natalia C, Ratih PS, Haswiyanti. (2014). Gambaran Tingkat Pengetahuan Pasien tentang Cara Penggunaan dan Penyimpanan Obat Tetes Mata Di Apotek Perintis Kuripan Banjarmasin. Tersedia online di http://repository.akfar-isfibjm. ac.id/176/1/Cynthia\%20Natalia.pdf.

UPT Pelayanan Kesehatan. (2018). Cara Menggunakan Obat Tetes Mata. Tersedia online di https:// yankes.itb.ac.id/informasi/cara-menggunakanobat-tetes-mata/

Direktorat Bina Penggunaan Obat Rasional. (2008). Materi Pelatihan Peningkatan Pengetahuan Dan Keterampilan Memilih Obat Bagi Tenaga Kesehatan. Departemen Kesehatan Republik Indonesia.

Kurniawansyah IS, Sopyan I, Subarnas A, Rusdiana T, Gozali D, dkk. (2018). Penggunaan Obat Mata Yang Rasional Di Desa Cilayung Kecamatan Jatinangor. Jurnal Pengabdian Kepada Masyarakat. 2 (1) 41-43. 